\title{
Net Neutrality and scenarios of Internet Pricing
}

\author{
MALOBA MBUYA Firmin ${ }^{1}$ \\ ${ }^{1}$ Institut supérieur de Statistique de Lubumbashi /Département Informatique \\ Lubumbashi, Democratic Republic of Congo
}

\begin{abstract}
This article analyzes the comparisons of net neutrality with the pricing of the Internet. We note that the future threats of congestion which call for the renewal of the infrastructure are accompanied by a search for lucre from the operators of the Internet. This tendency has the ambition of creating a deep discrimination of the Internet by imposing pricing at the interoperator level as well; at the level of the application, content and service providers rather than that of the users.
\end{abstract}

This leads us to glimpse through the prospective method that highly discriminatory and anti-neutral scenarios will ultimately be characterized by individualized pricing.

Keywords: net neutrality, discrimination, price, scenario.

\section{Introduction}

In 2012, Internet traffic forecasts projected a significant increase of $30-35 \%$ per year for fixed and $60 \%$ per year for mobile whereas $20 \%$ of subscribers accounted for $90 \%$ of traffic (1). This has completely changed the relationships between individuals of all races, all religious affiliations and all social classes. There is now a category of workers directly attached to the Internet to which we can associate home and itinerant workers. Already, the Internet of objects is growing with the ability to connect objects to each other; Thus the prospective study of the general commissariat for strategy and foresight (2) (France) estimates to 2.5 billion the number of Internet users and 9 billion the number of connected objects.

The principle of neutrality recommends (2) that all traffic circulating on the network be treated equally and nondiscriminatory regardless of content, application, service, transmitter, receiver or equipment.
We can see that numerous scientific publications have emerged to underline the importance of net neutrality and its contribution in the development of users.

It is in particular the shaping of the debate on net neutrality through subsidized information (3), the principles, conditions and forms of net neutrality (4) (5) (6).

This problem, which puts Internet stakeholders in opposition, remains central to academics, industry and the various digital actors around the quality of the Internet service to be guaranteed to end-users, the taxation of service providers, Regulation of the Internet by States, interaction of Internet access providers of the last kilometer, access of users to the network and contents, and finally copyright, intellectual property, intellectual works of digital as well as the privacy of Internet users.

In this perspective, with an Internet without neutrality, the user could be forbidden to publish a blog because he did not subscribe to the payment as a content provider, or that he would be prohibited to download a file because it has not subscribed to an offer authorizing the download, or that it would be prohibited from using an online application because its provider voluntarily discriminated against any traffic from the site from which the resource is offered to him or just some free online library would become paying in order to bear the cost to pay his supplier. On the other hand, it would be difficult to know that after the multiple interconnections a service, an application or a content requested by the user is authorized by all the networks on which it passes.

This study is in continuity with the research on the sustainability of the founding principles of the Internet, the objective of which is to guarantee equal and nondiscriminatory treatment of trafficking in the provision of 
Internet access services (7) (6). Thus, we analyze the scenarios of pricing of the Internet by specifying those that have the vocation to discriminate access.

In this sense, with regard to net neutrality, the problematic of our research revolves around the fundamental question of what modalities of Internet tariffs are profiled in a near horizon.

To achieve the objectives assigned to this research, we use inductive methods. We use particularly the techniques of direct observation and the documentary technique. To this end, we use the concepts and summaries of various scientific literature, norms and laws.

The strategic analysis of neutrality was carried out using conventional strategic diagnostic tools such as brainstorming and foresight. Thus we approach morphological analysis and analysis of pricing scenarios using MS-Excel 2010, Mactor and Multipol software.

Our field of study is delimited within the framework what we call the community of the Internet which gathers all the actors who have a role to play around the Internet; The Internet as a community of people, interconnected computers infrastructures where applications, contents and services are used and produced.

\section{Concepts on Net Neutrality}

More than a medium of communication and information, the Internet is a political form in its own right, based on the sharing of knowledge, virtual communities, the anonymity that must today negotiate the shift of the "massification" through the Internet of objects without compromising the founding ideals

The physical architecture of the Internet consists of the hardware infrastructure for interconnection and termination of connected networks. The means of access fall into three categories:

- Backbone access, these are the parts of the network consisting of long distance links at very high speed;

- Access to networks of local loop operators, which correspond to all the means used by an operator to collect user traffic; in the case of cellular and Wimax technologies, the radio local loop makes it possible to offer access to a large number of subscribers at a relatively low cost and;
- The means provided to the user to connect his own computer sites. It may be a wired network, a switched telephone network, a cable network, an optic fiber network or a wireless network offering satellite access, or a mobile network, Wi-Fi or Wimax.

The logical architecture of the Internet is composed of the stack of TCP / IP protocols and communication standards allowing the transport of data over the networks. It is a set of protocols to solve interconnection problems in a heterogeneous environment. (9). The TCP / IP protocol stack (RFC 1122) corresponds to the overlay of several layered protocols and the most important protocols of which are TCP (RFC 793) transmission control protocol and IP (RFC 791) Internet protocol Packages according to the best effort policy. Information is transmitted over the Internet through a standardized set of data transfer protocols, the core of which is TCP / IP, enabling the development of various applications and services such as email, instant messaging. (9) To satisfy transmission requirements, the Internet requires the following conditions: packet formatting, addressing, routing, forwarding, error correction. (10). Another feature of the Internet is the essential "end-to-end" principle, which embodies the end-to-end architecture, for which network intelligence is located at the end of the mesh and not centralized.

One of main ways to access the Internet is the web. Historically, the web has been developed around three technologies: the http protocol (Hypertext transfer protocol), the hypertext markup language (html), and the uniform resource locator (11). The first components of the Web were designed in October 1990 by Tim Berners Lee and Robert Caillau for CERN (European Center for Nuclear Research) in Switzerland. The Web 2.0 introduced by Tim O'reilly has revolutionized the usage of web sites and applications in the Internet (20). The term semantic web attributed to Tim Berners-Lee refers to the web 3.0 where users would be relieved of much of the research using engines and meta- Search engines, combining and building results through increased capabilities of computers to access content and simulate coherent reasoning.

\section{Managed Services}

Traffic management is any technical from of intervention on the data flows implemented taking into account the nature of the traffic or the identity or the quality of its transmitter or recipient. 
This may involve traffic shaping (12), which consists in introducing a delay between the transmission of data packets from certain services, buffer management (13) (14), which consists in prioritizing or slowing down Certain applications, traffic scheduling, which consists in scheduling the transmission of certain application flows or in blocking the transmission of certain streams.

Managed services means any service providing access to applications, content and services by electronic means offered by an access provider which, under certain parameter conditions, benefits from improved characteristics. These are generally guarantees for better service provided by the ISP in terms of bandwidth, packet loss, jitter, latency or security.

Some services are classified under the category of managed services such as voice, ADSL / FTTH television, accessible via a television. These services generally benefit from an independent dedicated channel that supports Internet access.

Some types of virtual private networks, VPNs are also a managed service.

With the explosion of bandwidth demand many other services requiring quality of service want to differentiate themselves from the user. These may include audio-visual services, telemedicine, tele-presence, online video games, online voting.

\section{Classification of Applications by Demand in Quality of Service}

Table 1: Managed Services and Resource Demand

\begin{tabular}{|l|l|l|l|l|}
\hline $\mathrm{N}^{\circ}$ & Service/Application & Bandwidth & \multicolumn{1}{|c|}{ Latency } & \multicolumn{1}{|c|}{ Gigue } \\
\hline 1. & Mail & Low & Low & Low \\
\hline 2. & $\begin{array}{l}\text { File sharing (peer to } \\
\text { peer) }\end{array}$ & Medium & Low & Low \\
\hline 3. & Web browsing & Medium & Medium & Low \\
\hline 4. & Online games & Low & High & Medium \\
\hline 5. & Video on Demand & High & Low & High \\
\hline 6. & VoIP Calling & Low & High & High \\
\hline 7. & Video conference & High & High & High \\
\hline
\end{tabular}

\section{Economic Issues of Net Neutrality}

From an economic angle, the Internet is considered a twosided market (12) (7) where we find:

- Internet service providers (ISPs) managing infrastructures;

- Application, content and service providers (FACS) that pass through infrastructures to reach users;
- Users access different content, applications and services and can at times become content providers by producing blogs or through peer-to-peer exchanges.

Authors such as Christopher YOO (4), James B. Speta (B), who describe the problem of Internet interconnection around a comprehensive approach based on legal, technical and economic aspects, using a model that encompasses regulation and latitude left to the operators to direct the interconnection rights to the contents. They describe 3 effects:

- How networks would create value;

- The way in which network effects can create barriers to market entry;

- The manner in which network effects may affect innovation in an associated market.

The Internet is changing rapidly. All users tend to consume video and multimedia, requiring more bandwidth and physical network optimization. With an annual increase of $10 \%$ and an annual tripling of traffic demand, the question posed by operators is who pays for the maintenance and improvement of the capacity of the Internet. In the face of an exponential growth in bandwidth, ISPs are tempted to orient the best quality of service to the highest bidder.

Several factors explain this growth. This includes changing of the structure of the application. Traffic is growing tenfold as video applications, services and contents grow; online video games, teleconferencing applications and IP telephony.

Without the guarantee of optimal quality of service, these applications cannot function properly. Many FACS would be willing to pay the surplus in order to benefit from superior quality of service.

Unfortunately, respect for the principle of the net neutrality is an obstacle when ISPs intend to sell prioritization.

Currently traffic growth exceeds the growth of existing network capacity (13). This would pose in the long term, a problem of congestion of the Internet.

To solve the problem of congestion, ISPs are considering two solutions.

A first solution is the blocking of flows, which consists in filtering or blocking certain flows. This technique is completely opposed to the principles of net neutrality because it induces discrimination between the different providers of content and between the different data that transit the network. 
A second solution is to invest in network capacity by increasing the capacity of the network through investment in infrastructure.

It is in this context that ISPs support a two-tier Internet. On the other hand, verticality, spelled out 46 times by the European consortium of ISPs (17), deviates towards a problem of economic income in that operators, Internet Service Providers (ISPs) want to benefit from the sale of sponsored links Which FACS benefits through advertising. This alternative is all the more motivated because, at the same time, the FACS derives a no less important income from the users. It is also evident that it is true that some FACS services affect the direct and traditional revenues of ISPs. This is the case of VoIP applications, which causes some ISPs to discriminate this type of traffic on the network they manage.

In addition, ISPs argue that, in front of its ISP competitors; there is no economic incentive to discriminate traffic at the risk of losing its own customers.

5.1 Reduction of net neutrality in applications requiring quality of services

The management principle according to the best effort prohibits the differentiated management of the data flows.

In this context, all incoming and outgoing flows are treated in the same way regardless of the type, origin or destination. Content providers are all governed by the same quality of service.

Net neutrality thus prevents ISPs from:

- Block certain flows;

- Degrade the quality of the flows through their networks;

- Prioritize flows;

- Guarantee a certain quality of service to a FACS or a particular user.

However, these principles no longer apply in the strict sense. The implementation of methods and techniques for filtering in order to limit certain flows that could impair safety is first limiting net neutrality. On can thus cite techniques such as:

- Packet sniffing;

- Deep packet inspection, to open all the packets that convey the data exchanged with servers or users in order multidimensional.

Indeed, prioritization by ISPs is extremely risky. There is a definite risk of becoming a barrier for newcomers to the Internet and content market. Many analyze point out that the competitive intensity in the access market would guarantee the respect of the principle of neutrality by the operators by ensuring a form of self-regulation and preventing the appearance of anticompetitive drifts. On the other hand, effective control by the competent authorities of the quality of service is difficult to implement given the opacity prevailing in the data interconnection market

For example, many FACS have opted for Edge caching solutions to store content that is most in demand close to use through the CDN (Content Delivery Networks) that they can disseminate on the crossroads of Information.

5.2 Challenges to the net neutrality by need to invest in infrastructure

Access to the Internet has been guided by a basic principle that access providers should not control traffic flowing through their networks. De facto, this is a rule that Tim $\mathrm{Wu}$ calls the "zero price" that prohibits the ISP from charging additional charges to a content provider (7). Historical reasons do not economically justify the principle. A convincing justification appears in the economic theory of two-pole markets, where the Internet is considered a market or intermediary between two main groups; users and content providers.

Supporting the cost of investing in infrastructure impose a pricing method. Thus, four scenarios of pricing are currently applied.

- A pricing based on the consumption of the user would have the advantage of empowering the users in relation to their consumption and in relation to the congestion caused in the network. However, congestion problems arise only at busy times and at certain points in the network;

- Generic flat rate pricing at fixed prices supported by the user;

- Specific pricing higher than what the user would pay for by the provider of services, applications and content;

- Specific pricing supported by both the user and the provider of services, applications and contents. 
IJCSI International Journal of Computer Science Issues, Volume 14, Issue 1, January 2017

\section{Results}

\subsection{Net distances between actors}

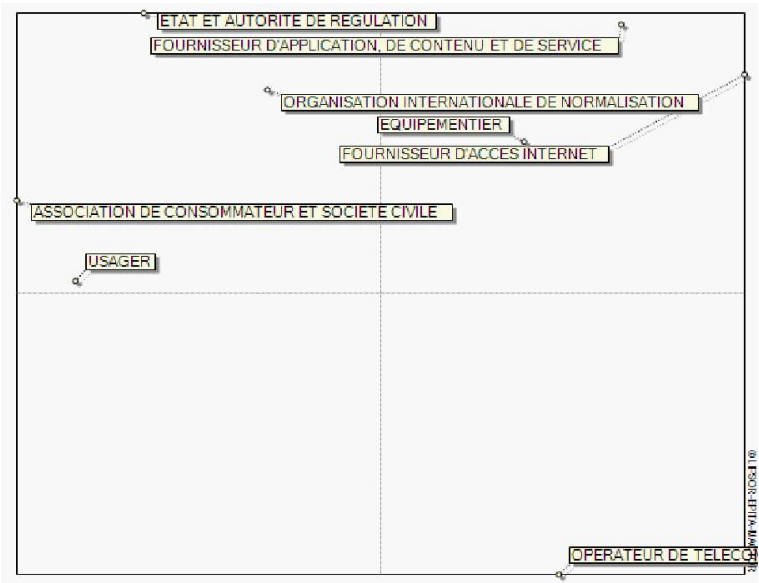

Fig. 1 Net distance between actors

\subsection{Graph of net distances between actors}

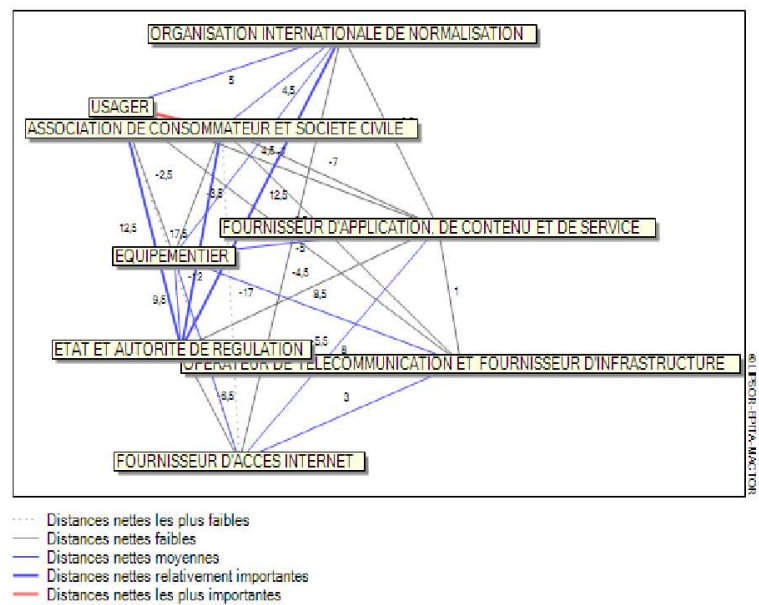

Fig 2. Graph of net distance between actors

The graph of the net distances between actors represents the potential alliances taking into account the divergences and convergences between actors of order 2 .

Thus, the input actors that impact the neutrality and pricing of the Internet are the users, the State and the regulatory authority, as well as the consumer associations and the civil society in exit we have the operators of telecommunications and Infrastructure providers, intermediary players are Internet service providers, equipment manufacturers, application, contents and service providers.
6.1 The field of possibilities

Table 2: Possible scope for net pricing

\begin{tabular}{|c|c|c|}
\hline $\mathrm{N}^{\circ}$ & Components & Configuration \\
\hline \multirow[b]{4}{*}{1} & \multirow{4}{*}{$\begin{array}{l}\text { Intercom } \\
\text { billing }\end{array}$} & 1. No tariffs - Free access \\
\hline & & 2. Peering Agreement \\
\hline & & 3. Peering Fee Schedule \\
\hline & & 4. Individual pricing \\
\hline \multirow[b]{4}{*}{2} & \multirow{4}{*}{$\begin{array}{l}\text { Billing of the } \\
\text { operator } \\
\text { To the ISP }\end{array}$} & 1. No tariffs - Free access \\
\hline & & 2. Transit Agreement \\
\hline & & 3. Peering Fee Schedule \\
\hline & & 4. Individual pricing \\
\hline \multirow[b]{4}{*}{3} & \multirow{4}{*}{$\begin{array}{l}\text { ISP billing at } \\
\text { FACS }\end{array}$} & 1. No tariffs - Free access \\
\hline & & 2. Fixed payment \\
\hline & & 3. Fee Schedule \\
\hline & & 4. Individual pricing \\
\hline \multirow[b]{4}{*}{4} & \multirow{4}{*}{$\begin{array}{l}\text { Billing of the } \\
\text { ISP to the } \\
\text { User }\end{array}$} & 1. Free access \\
\hline & & 2. Fixed payment \\
\hline & & 3. Fee Schedule \\
\hline & & 4. Individual pricing \\
\hline \multirow[b]{5}{*}{5} & \multirow{5}{*}{$\begin{array}{l}\text { Choice of } \\
\text { ISP by user }\end{array}$} & 1. choice oriented princing \\
\hline & & 2. Proximity Choice \\
\hline & & 3. Choice of quality of service \\
\hline & & 4. Choice oriented need \\
\hline & & 5. Anti-discrimination-oriented choices \\
\hline \multirow[b]{5}{*}{6} & \multirow{5}{*}{$\begin{array}{l}\text { Choice of } \\
\text { FACS by } \\
\text { user }\end{array}$} & 1. Choice of open access application \\
\hline & & 2. Choice of Crowdsourcing \\
\hline & & $\begin{array}{l}\text { 3. Choice of paid application, content or } \\
\text { service }\end{array}$ \\
\hline & & 4. Choice of features \\
\hline & & 5. Other choices \\
\hline \multirow[b]{5}{*}{7} & \multirow{5}{*}{$\begin{array}{l}\text { Regulatory } \\
\text { Actions }\end{array}$} & 1. No legal discrimination \\
\hline & & 2. Security discrimination \\
\hline & & 3. Congestion Discrimination \\
\hline & & 4. Congestion and legal discrimination \\
\hline & & 5. Service Discontinuance Decision \\
\hline \multirow[b]{4}{*}{8} & \multirow[b]{4}{*}{$\begin{array}{l}\text { Action of the } \\
\text { OEM }\end{array}$} & 1. Availability of equipment (sale, rental) \\
\hline & & $\begin{array}{l}\text { 2. Association ISP-Equipment } \\
\text { manufacturer }\end{array}$ \\
\hline & & $\begin{array}{l}\text { 3. Association operator --Equipment } \\
\text { manufacturer }\end{array}$ \\
\hline & & $\begin{array}{l}\text { 4. Conversion of the equipment } \\
\text { manufacturer into a user }\end{array}$ \\
\hline \multirow[b]{5}{*}{9} & \multirow{5}{*}{$\begin{array}{l}\text { Billing of the } \\
\text { FACS to the } \\
\text { User }\end{array}$} & 1. Free access \\
\hline & & 2. Donation and/or Crowdsourcing \\
\hline & & 3. Fixed payment \\
\hline & & 4. Fee Schedule \\
\hline & & 5. Individual pricing \\
\hline
\end{tabular}

Either $4 \times 4 \times 4 \times 4 \times 5 \times 5 \times 5 \times 4 \times 5=640000$ possible scenarios 


\subsection{Schematic of Tariff Scenario}

\section{Table 3 : Pricing scenarios}

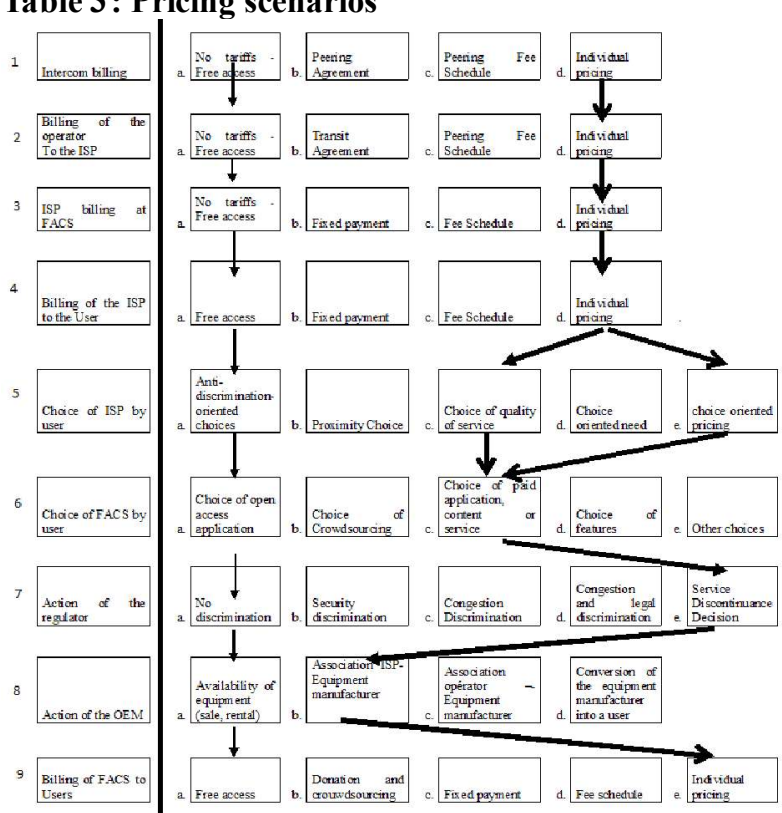

\section{Discussion}

Given the power relations between actors, we find that consumer associations and civil society play a central role in the neutrality of the Internet; because they influence the state and put a certain pressure on the telecommunications operators and ISPs.

On the other hand, the state is ambivalent. It is an actor who defends both the interests and freedoms of users' access to users and must ensure favorable economic conditions for equipment manufacturers, telecommunications operators, Internet service providers and content application providers, Application and / or services, while guaranteeing safety for all.

Concerning the pricing scenarios, he sees that certain scenarios which materialize the free access by the user are less realistic and therefore to exclude. This is the case of Scenario 1.a.; 2.a.; 3.a. 4.a; 5.a; 6.a. 7.a. 8a 9.a. because in the hypothesis of offering the services in the free and without regulation. The risk of congestion is therefore obvious.

Scenarios that offer individual pricing will have to favoring certain users, suppliers, applications, services and contents. They are therefore discriminatory and encroach on net neutrality.
Scenario 1.d.; 2.d.; 3.d. 4.d. ; 5.c. or 5.e. ; 6.c 7.e. 8.b 9.e. is the one with the greatest discrimination. It would create a multi-tier, multi-tiered Internet where every actor, operator, vendor would be served on demand and yet one could not predict that the highest bidder would be best served.

As for the peering agreements, if they are taken individually between operators, without regulation, this will be a cause of segmentation of the network into portions of privileged and less privileged, which hampers the founding principles of the Internet.

In order to support innovation and net neutrality, the point to be maintained in the current situation would be free access from application, content and service providers, all the more so that the latter pays taxes and fees operating in relation to the services it provides.

The diversification of supply is conditioned on essential aspects:

- Diversification should not lead to a segmentation and a "rigidification" of the offer likely to make the users captive of their ISPs;

- Diversification must be varied to allow for the needs of users to be taken into account.

However, the offer must be readable and understandable to allow everyone to make his choice and also, not complex to allow comparisons. The better your paper looks, the better the Journal looks. Thanks for your cooperation and contribution.

\section{Conclusion}

There is a danger of the Internet at several speeds where the more affluent may acquire the bulk of the resources. Another aspect is that of transforming OEMs into Internet users who would offer services such as the Internet of objects.

The outlook for tariffs presents less probable assumptions such as free and unregulated access, but also scenarios with highly discriminatory access where individual tariffs apply.

\section{References}

[1] Emmanuel SARTORIUS, Dominique VARENNE, Maurice SPORTICHE. Les besoins en bande passante et leur évolution. Paris : Ministère Français de l'Economie et 
des Finances, Conseil Général de l'Economie, de l'Industrie, de l'Energie et des Technologies, 2012.

[2] Antton Achiary, Dominique Auverlot, Joël Hamelin. internet : prospective 2030. [éd.] Commissariat général à la stratégie et à la prospective. La Note d'analyse $n^{\circ} 2$. $1 \mathrm{er}$, 2013, Vol. 02. www.strategie.gouv.fr.

[3] Règlement UE 2009/2120 du parlement Européen et du Conseil du 25 novembre 2009, établissement des mesures relatives à l'accès à Internet ouvert modifiant la directive 2002/22/CE concernant le service universel et les droits des utilisateurs. J.O. de l'Union Européenne. Bruxelles : s.n., 25 novembre 2009, J.O. de l'Union Européen L 310 du 26/11/2009, pp. $1-18$

[4] The Shapping of the Network Neutrality Debate: Information Subsidizers on Twitter. KYUNG SUN LEE, WEIAI WAYNE XU. 2015, International Journal of Communication, pp. pp. 1544-1562.

[5] What Can antitrust contribute to the Network Neutrality Debate. Christopher S. YOO. 2007, International Journal of Communication, pp. pp. 493-530.

[6] Network Neutrality and Quality of Service : What a Nondiscrimination Rul Should Look Like. Barbara Van Schewick. 1, Stanford: s.n., 2606 2015, ForthComing, Stanford Law Review, Vol. 67.

[7] Network Neutrality broadband. Tim Wu. 2004, pp. 1-39.

[8] Subsidizing Creativity through Network Design : ZeroPricing and Net Neutrality. Robin S. Lee, Tim Wu. 3, 2009, Journal of Economic Perspectives, Vol. Volume 23, pp. 61-76.

[9] A common carrier approach to internet Interconnection. Speta, James B. 2, 2002, Federal communication law journal, Vol. 54, pp. 226-280. Article 2.

[10] Servin, Claude. Réseaux et télécoms, cours et exerices corrigés. Paris : Dunod, 2003.

[11] Geoffrey G. Xie. . (Geoffrey G. Xie, Department of Computer Science, NavalInternet Architecture: Lessons Learned and LookingForward. s.l. : Department of Computer Science, Naval Postgraduate School, 2006.

[12] Saint Jean Djungu. Outils et langages du Web n.0. [éd.] Médiaspaul. Kinshasa : Médiaspaul, 2013.

[13] Sivaraman, Vijay et Chiussi, Fabio. Improving battery performance by usign traffic shaping techniques. IEEE Journal on Selected Areas in Communications. 2001, Vol. 19,7 .

[14] BPLRU: A Buffer Management Scheme for Improving Random Writes in Flash Storage. FAST '08: 6th USENIX Conference on File and Storage Technologies. 6, 2008, pp. 239-252.

[15] Leonidas Georgiadis, Roth Guérin, Vinod Perk, Kumar N. Sivarajan. Efficient Network QoS Provisioning Based on per Node Traffic Shaping. IEEE /ACM
TRANSACTIONS ON NETWORKING. August 1996, Vol. 4, 4, pp. 482-501.

[16] Nicholas Economides, Joacim Tag. Network neutrality on the Internet : A two-sided market analysis. Information Economics and Policy. 2012, pp. 91-104.

[17] DECRUYENAERE, Thibault. La neutralité de l'Internet et ses enjeux économiques. Paris : République Française, Document de travail de la Direction Générale du Trésor, 2011.

[18] Opérateurs télécoms européens. Manifesto for timely deployment of 5G in Europe. [En ligne] 07072016.

[19] Godet, Michel. Manuel de prospective stratégique. 3è. Paris : Dunod, 2007. p. 427. Vol. Tome 2.

[20] Anouar Abtoy, Noura Aknin, Boubker Sbihi, Ahmed El Moussaoui and Kamal Eddine El Kadiri, Content validation as a tool for new pertinent web 2.0 blogs, International Journal of Computer Science Issues, vol.9 Issue 3, No 3, May 2012, (www.ijcsi.org)

[21] ETTUGHOFFER, Denis C. L'économie numérique serat-elle sous domination américaine. Géoéconomie , Printemps 2010. 2010, pp. 1-11.

[22] Le problème de la neutralité du Net est-il réglé? Patrick Maillé, Bruno Tuttin. 2014, HAL - 01001778, p. 6.

[23] Zwolinska, Monika. Sécurité et libertés fondamentales des communications électroniques en droit français, européen et international. Faculté de Droit, Université de Sophia Antipolis. Sophia : Université de Sophia Antipolis, 2015. p. 585. NNT 2015 NICE0038- TEL-01251984.

[24] Afonso, Carlos A. Gouvernance de l'Internet, une analyse dans le contexte du Sommet Mondial de la Société de l'Information. Montevideo : Institut du Tiers Monde, Juillet 2005. pp. 1-58.

[25]ARCEP. Qualité du service fixe d'accès à l'Internet Version-test (bêta) Mesures de la qualité du service fixe d'accès à l'Internet effectuées en juin 2014 , Arcep, 2014 p. 14). Paris : ARCEP, 2014

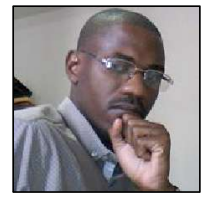

Maloba Mbuya Firmin, Bachelor (Hons) degree in Business Informatics from the Institut Supérieur de Statistique de Lubumbashi (Democratic Republic of Congo) in 2006. $\mathrm{He}$ is currently a postgraduate student in Mathematics and Computer Science at the University of Lubumbashi. His research interests Networks, Social Security and information Technology Applied Studies. Since 2006, he gives lectures and seminars in informatics at public and private private universities and colleges in D.R. Congo. 